ISSN 2072-6651

www.mdpi.com/journal/toxins

Retraction

\title{
Retraction: Reddy, K.R.N.; Abbas, H.K.; Abel, C.A.; Shier, W.T.; Salleh, B. Mycotoxin Contamination of Beverages: Occurrence of Patulin in Apple Juice and Ochratoxin A in Coffee, Beer and Wine and Their Control Methods. Toxins 2010, 2, 229-261.
}

Received: 28 April 2010 / Published: 28 April 2010

It has been brought to our attention by a member of our Editorial Board that substantial portions of this review article [1] have been copied verbatim from earlier publications without credit. After comparing the present paper and the other sources we have determined that indeed this manuscript clearly violates our policy on originality of all material submitted for publication and the generally accepted ethics of scientific publication. Consequently, the Editorial Team and Publisher have determined that it should be retracted. We apologize for any inconvenience this may cause.

Prof. Dr. med. Florian Lang

Editor-in-Chief, Toxins

Dr. Shu Kun Lin

Publisher, $M D P I$

\section{References}

1. Reddy, K.R.N.; Abbas, H.K.; Abel, C.A.; Shier, W.T.; Salleh, B. Mycotoxin Contamination of Beverages: Occurrence of Patulin in Apple Juice and Ochratoxin A in Coffee, Beer and Wine and Their Control Methods. Toxins 2010, 2, 229-261; doi: 10.3390/toxins2020229.

(C) 2010 by the authors; licensee Molecular Diversity Preservation International, Basel, Switzerland. This article is an open-access article distributed under the terms and conditions of the Creative Commons Attribution license (http://creativecommons.org/licenses/by/3.0/). 